\title{
National Institute for Health Research (NIHR) Health Technology Assessment (HTA) Programme research funding and UK burden of disease
}

\author{
Fay Chinnery ${ }^{1 *}$ D, Gemma Bashevoy ${ }^{2}$, Amanda Blatch-Jones', Lisa Douet ${ }^{2}$, Sarah Puddicombe $^{2}$ and James Raftery ${ }^{1}$
}

\begin{abstract}
Background: HTA Programme funding is governed by the need for evidence and scientific quality, reflecting funding of the National Institute for Health Research (NIHR) by the NHS. The need criterion incorporates covering the spectrum of diseases, but also taking account of research supported by other funders. This study compared the NIHR HTA Programme portfolio of research with the UK burden of disease as measured by Disability-adjusted Life Years (DALYs).

Methods: A retrospective cross-sectional study using a cohort of all funded primary research and evidence syntheses projects received by the HTA Programme from April 2011 to March $2016(n=363)$; to determine the proportion of spend by disease compared with burden of disease in the UK calculated using 2015 UK DALY data.

Results: The programme costing just under $£ 44$ million broadly reflected UK DALY burden by disease. Spend was lower than disease burden for cancer, cardiovascular and musculoskeletal diseases, which may reflect the importance of other funders, notably medical charities, which concentrate on these diseases.

Conclusion: The HTA Programme spend, adjusted for other relevant funders, broadly matches disease burden in the UK; no diseases are being neglected.
\end{abstract}

Keywords: Burden of disease, Disability-adjusted life years, National Institute for Health Research, Health Technology Assessment Programme, Funding

\section{Background}

Comparing funding to the burden of disease, as measured by Disability-adjusted Life Years (DALYs), has been used to assess the appropriate spread of spending. DALYs take into account both the potential years of life lost due to premature death and equivalent years of healthy life lost by virtue of being in states of poor health or disability [1]. Previous studies comparing United States (US) National Institutes of Health $(\mathrm{NIH})$ funding to burden of disease have shown DALYs to be the single best correlate with spend by disease [2]. Other studies have focussed on the association between randomised trial or systematic review evidence and global burden of disease [3-5].

\footnotetext{
* Correspondence: F.Chinnery@soton.ac.uk

'Wessex Institute, University of Southampton, Alpha House, University of

Southampton Science Park, Southampton SO16 7NS, UK

Full list of author information is available at the end of the article
}

The UK Clinical Research Collaboration (UKCRC) undertook an analysis of public funding of health relevant research in the UK in 2014 [6]. The analysis included funding by 64 organisations such as the government, charities and UK Research Councils (RCUK), corresponding to over $£ 2$ billion of investment. Figure 1 summarises the UKCRC results, by descending DALYs. Of the four disease categories with the largest DALY burden, only public spend on the Cancer category is closely correlated with the burden of disease in the UK, and the majority of this support is provided by charities.

Funding by the Department of Health (UK government) covered 29 departments, but most of the funding was for infrastructure, rather than research. The National Institute for Health Research (NIHR) Health Technology Assessment (HTA) Programme is included among the 29 Department of Health departments. The HTA Programme is the 


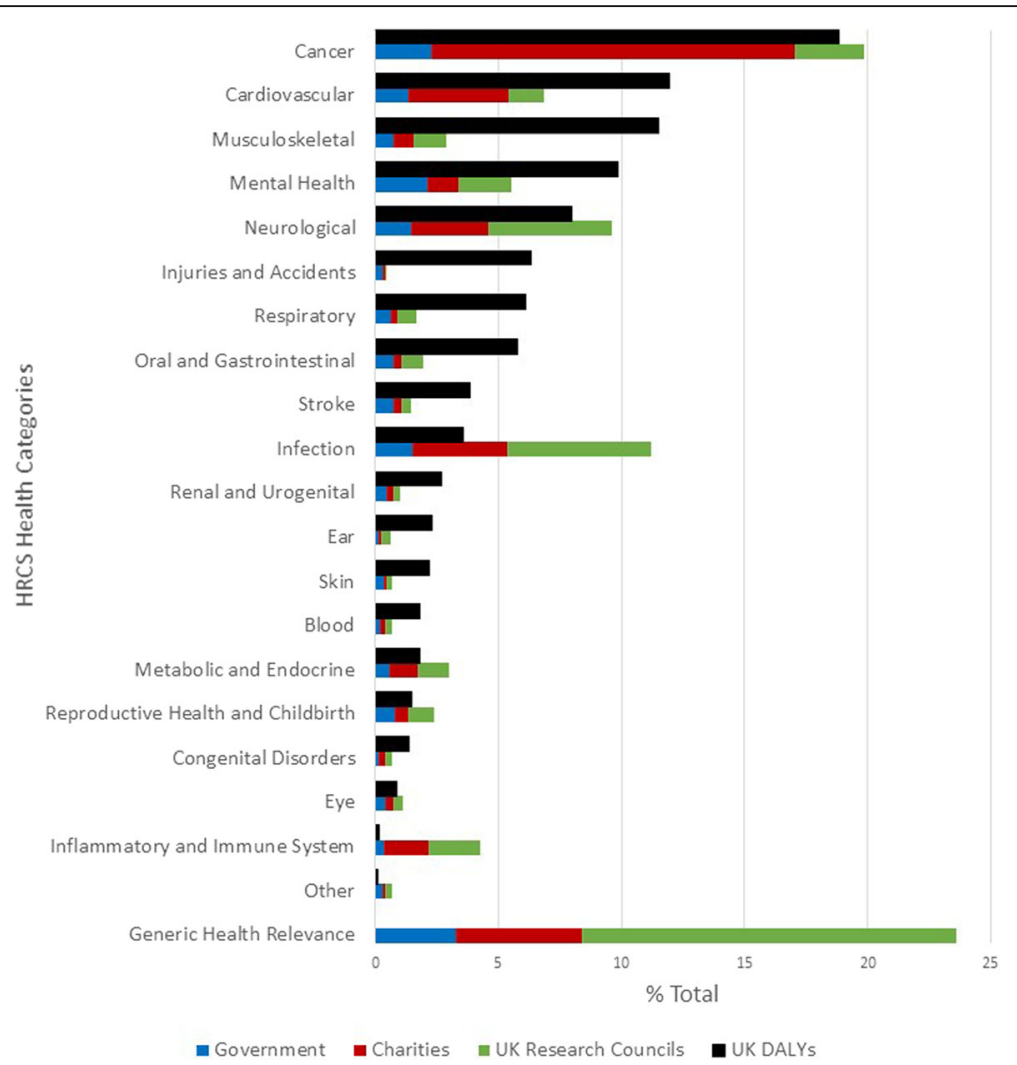

Fig. 1 UK public-funder spending compared with UK burden of disease (Disability-adjusted Life Years; DALYs) mapped to Health Research Classification System (HRCS) health categories

largest and longest-running NIHR research programme, it mainly funds research trials and systematic reviews of the clinical and cost-effectiveness, of health technologies.

Criteria for HTA Programme funding are (1) the need for evidence and (2) scientific quality, reflecting funding of the NIHR by the NHS [7]. The need criterion has two implications: coverage of the spectrum of diseases, but also taking account of research supported by other funders. The latter include the UK's disease-specific medical charities, the biggest of which cover cancer, cardiovascular and musculoskeletal diseases. Consequently, one would expect HTA Programme spend to be well spread across diseases, but relatively lower in those diseases which have substantial charity funding. This paper compares HTA Programme spend with the UK burden of disease as an indicator of 'need'.

\section{Methods}

\section{Data source and classification of disease}

Age-standardised 2015 DALY data for the UK (all ages and both sexes) from the Institute for Health Metrics and Evaluation Global Health Data Exchange were used [8]. These data for 316 specific diseases were assigned to the 21 Health Research Classification System (HRCS) health categories (which are derived from the World
Health Organisation International Classifications of Diseases) independently by two of three coders (GB, LD and AB-J; data available in Additional file 1). Any disagreements were resolved in discussion with the third coder. The nature of the HRCS prevents dual coding. If a disease falls into two or more HRCS categories, the disease is apportioned equally between the two codes. For example, cellulitis is coded as $50 \%$ Infection and 50\% Skin in HRCS. This coding gave a DALY estimate for each health category, allowing the percentage of the total burden of disease in the UK for each category to be calculated.

\section{Sample selection}

All funded primary research and evidence syntheses projects received by the HTA Programme between 1 April 2011 to 31 March 2016 were included $(n=363$; data available in Additional file 1).

All funded applications received by the HTA Programme are routinely coded using the HRCS. If the disease described in an application falls into two different HRCS categories, the project is apportioned equally between the assigned codes. For example, a project concerning diabetic retinopathy would be coded as 50\% Eye and 50\% Metabolic and Endocrine. 


\section{Data analysis}

HTA Programme spend data were derived from the NIHR Evaluation, Trials and Studies Management Information System (NETS MIS) and mapped to DALY data using HRCS health categories. All analyses were in Excel 2013.

Costs included research costs only.

\section{Results}

Three hundred and sixty-three projects were identified for analyses; 277 were randomised controlled trials (RCTs). Total spend was just under $£ 400$ million and RCT spend was $£ 354$ million (Table 1). HTA Programme total spend (by HRCS category) was compared with 2015 UK DALYs (Fig. 2).

Total spend across the 21 health categories was fairly well correlated with their DALY burden, (simple linear regression; $r^{2}=0.61$; 95\% confidence interval (CI) 0.36-0.82).

Cancer (19\%), Cardiovascular (12\%) and Musculoskeletal (12\%) categories represent the largest disease burden in the UK, but the proportion of HTA Programme spend was considerably lower than the associated DALY percentage (Fig. 2). Disease areas well supported by the medical charities are marked by a red border in Fig. 2 indicating that any shortfalls in these disease categories were to some extent compensated for by the medical charities

Spend by the HTA Programme was higher in Mental health, Infection, Reproductive health and Childbirth, Renal and Urogenital and Eye categories than their associated DALY percentage (Table 1).

\section{Discussion}

HTA Programme spend broadly supports DALY burden by disease in the UK; no diseases are being overlooked, either in terms of total spend or from the perspective of RCT spend (Additional file 2). Discrepancies between DALYs and spend by the HTA Programme are compatible, with the latter funding less research in diseases supported by the medical charities.

\section{Strengths and limitations}

The main strength of the study was the inclusion of 363 research projects over a 5 -year period. This reduced the variation that could otherwise be caused by funding a few expensive projects in a short period of time, or the effects of NIHR research priority calls which could cause spikes in certain disease areas.

Table 1 National Institute for Health Research (NIHR) Health Technology Assessment (HTA) Programme total spend and randomised controlled trial (RCT) spend compared with the burden of disease (Disability-adjusted Life Years; DALYs) mapped to Health Research Classification System (HRCS) health categories

\begin{tabular}{|c|c|c|c|}
\hline HRCS health category & Total apportioned spend $(£)$ & RCT apportioned spend (\%) & DALY burden (\%) \\
\hline Cancer & $48,141,582$ & $43,289,092$ & 18.84 \\
\hline Cardiovascular & $36,492,300$ & $32,422,740$ & 11.92 \\
\hline Musculoskeletal & $24,978,542$ & $21,728,235$ & 11.53 \\
\hline Mental health & $46,745,011$ & $43,758,644$ & 9.83 \\
\hline Neurological & $27,610,923$ & $26,963,249$ & 7.99 \\
\hline Injuries and Accidents & $21,045,089$ & $19,834,241$ & 6.33 \\
\hline Respiratory & $19,322,359$ & $14,646,317$ & 6.12 \\
\hline Oral and Gastrointestinal & $16,654,803$ & $14,152,800$ & 5.79 \\
\hline Stroke & $15,093,925$ & $14,841,635$ & 3.84 \\
\hline Infection & $34,490,269$ & $30,806,401$ & 3.58 \\
\hline Renal and Urogenital & $26,762,773$ & $23,925,063$ & 2.66 \\
\hline Ear & $1,947,835$ & $1,243,473$ & 2.31 \\
\hline Skin & $11,626,036$ & $11,527,412$ & 2.16 \\
\hline Blood & $1,178,448$ & $1,097,847$ & 1.80 \\
\hline Metabolic and Endocrine & $8,287,045$ & $6,602,431$ & 1.79 \\
\hline Reproductive health and Childbirth & $29,248,437$ & $26,391,283$ & 1.45 \\
\hline Congenital disorders & $1,928,151$ & $1,463,336$ & 1.35 \\
\hline Eye & $14,971,063$ & $10,276,840$ & 0.89 \\
\hline Inflammatory and Immune & $1,069,161$ & $1,069,161$ & 0.16 \\
\hline Other & 994,430 & 994,430 & 0.08 \\
\hline Generic health relevance & $8,623,682$ & $7,281,761$ & 0.00 \\
\hline Total & $397,211,864$ & $354,316,391$ & 100 \\
\hline
\end{tabular}




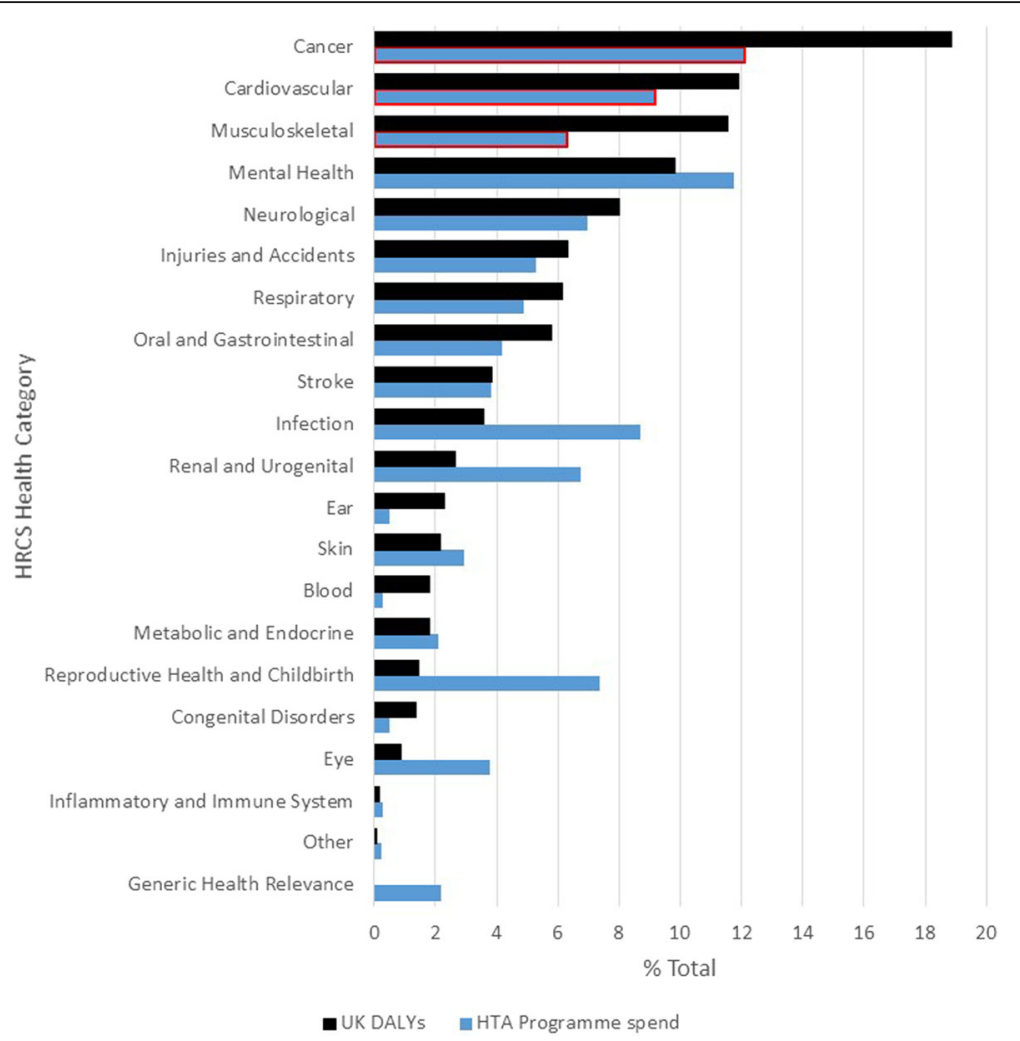

Fig. 2 National Institute for Health Research (NIHR) Health Technology Assessment (HTA) Programme spend compared with UK burden of disease (Disability-adjusted Life Years; DALYs) mapped to Health Research Classification System (HRCS) health categories

A limitation of the study was the use of DALYs, which are crude measures of overall disease burden, and do not capture the wider effects of interventions such as Quality of Life, impact on carers and family, or nonhealth effects such as economic and social consequences (such as loss of work) $[9,10]$.

\section{Implications}

As expected, there was a lower proportion of HTA Programme spend for cancer, cardiovascular and musculoskeletal diseases. These three disease categories have funding by three large medial charities: Cancer Research UK, British Heart Foundation (BHF) and Arthritis Research UK. The largest medical charity, the Wellcome Trust, supports research across all diseases [6].

There were a number of diseases where HTA Programme spend was greater than the burden of disease, including Infection, Reproductive health and Childbirth, Renal and Urogenital and Mental health categories. These research topics have been neglected historically. For example, national and global underinvestment in mental health and infectious diseases has been noted [11, 12].

The relationship between DALY data, allocation of research funding and improvements in health is likely to be complex because health problems are not all equally set for research advances [13]. Diseases vary by the existence of interventions that might be usefully evaluated.

Increased research funding for a disease may not automatically reduce the burden of disease. An analysis of $\mathrm{NIH}$ funding and its correlation with US health dynamics over 50 years found that increased funding for heart disease and stroke was associated with reduced burden of disease; but there were no clear associations for cancer and diabetes [14]. In addition, spend may not be the most appropriate measure to compare with burden of disease because projects vary in cost, with trials costing much more than systematic reviews.

\section{Strengths and limitations}

- A large cohort of 5 years' of research funded by a major funder of health research in the UK

- DALYs only partly capture the effects of interventions on Quality of Life, on carers and family, and economic and social consequences (e.g. loss of work)

\section{Conclusions}

DALY analysis is a useful screen to see if any disease areas are being neglected, and so is of value when looking at the spread of funding by individual funders. Our 
results suggest that there are no major concerns for the spread of HTA Programme spending.

Other funders may find it useful to perform a similar DALY analysis. However, funding organisations should not align their spend directly against disease burden using DALYs, given that there may be a lack of worthwhile interventions to test in some diseases, and that research may already be well supported by other organisations.

\section{Additional files}

Additional file 1: 2015 DALYS coded to HRCS and HTA programme spend raw data. (XLSX $101 \mathrm{~kb}$ )

Additional file 2: HTA programme RCT spend. (JPEG $75 \mathrm{~kb}$ )

\section{Acknowledgements}

The authors would like to thank: Paul Biggins for developing the report to extract the funding data from the NETS MIS and for his support in ensuring robust data to underpin the project; Andrew Cook for his advice in the earlier development of the work

\section{Funding}

This research was supported by the NIHR Evaluation, Trials and Studies Coordinating Centre (NETSCC) through its Research on Research programme. The views and opinions expressed are those of the authors and do not necessarily reflect those of the Department of Health, or of NETSCC.

\section{Availability of data and materials}

All data generated or analysed during this study are included in this published article and its Additional files.

\section{Authors' contributions}

FC updated the data analysis using 2015 GBD data and information about HTA Programme-funded research from 2011 to 2016. She drafted the final version of the manuscript. GB undertook the initial acquisition, analysis and interpretation of original data (2013 GBD data; HTA Programme spend 2010-2015). She wrote the first version of the manuscript (using original data) and reviewed the final version. $A B J$ interpreted original data with $G B$, edited the first version of the manuscript, critically reviewed data content in the first version of the manuscript and reviewed the final version of the manuscript. LD advised the team on methodology and commented on iterations of the manuscript. SP guided development of the report to generate the DALY vs HTA Programme spend analysis, verified the accuracy of the spend report data, advised the team on content of the first version of the manuscript and reviewed iterations of the manuscript. JR advised the team on methodology and edited the final version of the manuscript. All authors read and approved the final manuscript.

\section{Ethics approval and consent to participate}

Not applicable.

\section{Consent for publication}

Not applicable.

\section{Competing interests}

FC is employed by the Wessex Institute and works for the Research on Research programme; she also worked for the HTA Programme between 2012 and 2015. GB is employed by the NIHR Evaluation, Trials and Studies Coordinating Centre (NETSCC), which hosts the HTA Programme, and is a research fellow in the Topic Identification Team. ABJ is employed by the Wessex Institute, leads the Research on Research programme and worked for the HTA Programme between 2008 and 2009. LD is employed by NETSCC and is a senior research fellow for the Efficacy and Mechanism Evaluation Programme. SP is employed by NETSCC and is the Assistant Director, Applications and Funding. JR is a professor of HTA at the Wessex Institute and is a member of the HTA Programme Editorial Board.

\section{Publisher's Note}

Springer Nature remains neutral with regard to jurisdictional claims in published maps and institutional affiliations.

\section{Author details}

${ }^{1}$ Wessex Institute, University of Southampton, Alpha House, University of Southampton Science Park, Southampton SO16 7NS, UK. ${ }^{2}$ National Institute for Health Research (NIHR), Evaluation, Trials and Studies Coordinating Centre (NETSCC), University of Southampton, Southampton SO16 7NS, UK.

Received: 18 September 2017 Accepted: 22 January 2018

Published online: 02 February 2018

\section{References}

1. WHO. Health statistics and information systems. Metrics: Disability-Adjusted Life Year (DALY). http://www.who.int/healthinfo/global_burden_disease/ metrics_daly/en/. Accessed 1 Feb 2017.

2. Gillum LA, Gouveia C, Dorsey ER, et al. NIH disease funding levels and burden of disease. PLoS One. 2011;6(2):e16837.

3. Emdin CA, Odutayo A, Hsiao AJ, et al. Association between randomised trial evidence and global burden of disease: cross sectional study (Epidemiological Study of Randomized Trials-ESORT). BMJ. 2015:350:h117.

4. Rottingen J-A, Regmi S, Eide M, et al. Mapping of available health research and development data: what's there, what's missing, and what role is there for a global observatory? Lancet. 2015;382(9900):1286-307.

5. Swingler GH, Volmink J, loannidis JP. Number of published systematic reviews and global burden of disease: database analysis. BMJ. 2003; 327(7423):1083-4.

6. UK Clinical Research Collaboration 2015. UK Health Research Analysis 2014. http://www.hrcsonline.net/sites/default/files/

UKCRCHealthResearchAnalysis2014\%20WEB.pdf. Accessed 1 Feb 2017.

7. Raftery J, Powell J. Health Technology Assessment in the UK. Lancet. 2013; 382(9900):1278-85.

8. Institute for Health Metrics and Evaluation. Global Health Data Exchange-GBD Results Tool. http://ghdx.healthdata.org/gbd-results-tool. Accessed 1 Feb 2017.

9. Sassi F. Calculating QALYs, comparing QALY and DALY calculations. Health Policy Plan. 2006;21(5):402-8

10. Anand S, Hanson K. Disability-adjusted life years: a critical review. J Health Econ. 1997;16(6):685-702.

11. Head MG. Gross underinvestment in antibacterial research. Lancet Infect Dis. 2014;14(9):788-9.

12. MQ Landscape Analysis. http://b.3cdn.net/joinmq/1f731755e4183d5337_ apm6b0gll.pdf. Accessed 1 Feb 2017.

13. Priority-setting processes_-Scientific opportunities and public needs. NCBI Bookshelf [Internet]. https://www.ncbi.nlm.nih.gov/books/NBK45366/. Accessed 1 Feb 2017.

14. Manton $\mathrm{KG}, \mathrm{Gu} X \mathrm{X}$, Lowrimore $\mathrm{G}$, et al. NIH funding trajectories and their correlations with US health dynamics from 1950 to 2004. Proc Natl Acad Sci U S A. 2009;106(27):10981-6.
Submit your next manuscript to BioMed Central and we will help you at every step:

- We accept pre-submission inquiries

- Our selector tool helps you to find the most relevant journal

- We provide round the clock customer support

- Convenient online submission

- Thorough peer review

- Inclusion in PubMed and all major indexing services

- Maximum visibility for your research

Submit your manuscript at www.biomedcentral.com/submit
Biomed Central 